\title{
No limits to imagining London's future
}

\author{
George Myerson and Yvonne Rydin
}

\section{Scenario development as a flawed compromise}

Scenario development is now an established industry, employing hordes of consultants. This way of considering the future is typically an exercise in compromise. Workshops bring 'stakeholders' together to discuss drivers and barriers, opportunities and challenges. Post-it notes - square, round, hexagonal - get stuck to wall charts. Timelines become populated with views, and guesses, on what will happen when. Axes of key cleavages between different futures get proposed and, almost inevitably, four different futures emerge out of the intersections of two main axes. At each stage there is discussion and debate, but perhaps not always in-depth deliberation or examination. Differences of opinion may be resolved, or they may be fudged. Group think can often dominate specific sessions. The resulting narratives will, of course, reflect a wide variety of knowledge but not necessarily great depth. They are the outcome of many different voices being melded into more or less coherent story-lines.

The result is inevitably a compromise narrative; and even with careful crafting, tensions, discontinuities and contradictions remain. Involving multiple voices in creating a narrative means that certain points get included, because someone has a strong view about that point, or just has the loudest voice. The consultant is tasked with smoothing out the differences and creating coherence, but it requires particular skills in close reading and textual analysis to do this. Because we all read and write, these skills are often under-appreciated, in a way that quantitative skills, in a largely number-phobic society, are not. In addition, the starting point for much futures thinking is frequently technological change, again privileging a particular way of looking at the world. Understanding how governance and society might change can be comparatively neglected in terms of really thinking about possible futures.

So what would be an alternative approach? One possibility - that being taken by the EPSRCfunded CLUES project (UCL, 2013) - is to find a way to enhance the coherence of scenarios that

\section{How to cite this book chapter:}

Myerson, G and Rydin, Y. 2013. No limits to imagining London's future. In: Bell, S and Paskins, J. (eds.) Imagining the Future City: London 2062. Pp. 155-158. London: Ubiquity Press. DOI: http://dx.doi. org/10.5334/bag.w 
have been developed through traditional workshop means. CLUES is using quantification as a means of teasing out the inherent inconsistencies in a set of existing scenarios to produce - it is argued - more robust and transparent scenarios. This has involved drawing on a wealth of published studies on likely future trends and validating this through discussion of quantitative tabular material within the research group and with external technical experts. Putting numbers to a narrative scenario poses questions which have to be answered with a degree of precision that really tests the scenario. The more bland statements of future trends are not accepted under this approach.

But a quite different approach is to dispense with the group means of scenario production, with its dependence on many diverse inputs from multiple experts, altogether. Instead, this approach involves relying on the individual imagination. This recognises the inherently artistic and creative nature of thinking about the future, and the need to root such an endeavour in the unfettered play of ideas, and trust to the coherence of a well-imagined story. The advantage of this approach is that is moves beyond the conservatism that is inherent in the workshop approach to scenario-building. It allows possibilities to be written that could not be said in a workshop, without nervous laughter and dismissal. It also dispenses with the sometimes spurious use of axes to structure scenario development, typically resulting in four such offerings. Each imagination is a sole contribution but there is no limit to how many can be developed. If the uncertain future is really being thought about, how much more realistic it is to consider one, three, six, twenty, fifty such offerings than be constrained by a matrix arrangement? In such offerings, all kinds of futures may be imagined. How many scenarios offered to policy makers to think through their options really consider the likelihood of a fascist state? How many consider radical new social values that would prioritise the views of children above those of adults? In the world of imagination, all futures are possible. So, in this spirit, here is one such imagining for London.

\section{London and the 5D football revolution}

After the Great Devaluation of 2018 had failed to 'kick start' the Anglo-Welsh economy, individual regions were given responsibility for many of the functions previously discharged by the central state, including health, education and many aspects of social security. The London Metropolitan Region became officially bankrupt in 2029 when the region's authority, led by Consul Boris Johnson together with his Liberal and Labour partners in the London Triumvirate, was unable to negotiate further help from the European Regional Aid Fund. Yet strangely this was the beginning of a development that led to full-scale independence for the City State of Urbanitas, comprising the previous area of Greater London together with the Oxbridge Corridors and the Windsor and Eton enclave. How was such immense success possible from such a low point?

The first signs of what was to come pre-dated the financial and fiscal crisis of '29, occurring in the education sector of the city. It was in this field that the city's most successful global institutions began to take responsibility for the widening holes in the increasingly ragged state networks. The earliest examples were the Chelsea FC Charitable Academies and the Arsenal FC Popular Free Elementary Schools. Then, as the resources drained from the coffers of the regional authority, the capital's football clubs stepped in and started to fund more and more of the public institutions, starting with the Hotspur Health Trusts in north London and accelerating with the giant Gunners Housing Association developments around King's Cross and the Blues Riverside Estates, built to commemorate the fifteenth champions league win of 2031, the final flourish of the legendary reign of Sir Roberto Di Matteo. This more socially-oriented development supplemented the massive and profitable investment that had gone into hotels, restaurants and conference venues by the clubs.

As the global financial role of the City of London faded into the imperial past, the three giant football corporations, as they became, were the only truly global financial players left. Their pros- 
perity was based on the expansion of the new 5D broadcast system, bringing the smell and touch, as well as the sight, of the match day to worldwide audiences of billions every week. The impetus for their foundational role in the establishment of Urbanitas began when the crowds started to decline in the aftermath of the great labour shake-out of '38, when the last financial trading companies left the now derelict Canary Wharf site, with the London Stock Market ceasing to trade the previous year. It became clear that without live crowds to sing and gesture and look picturesque, there was far less appeal to the new 5D match channel and the worldwide audience started to decline. In order to remedy this, the three football corporations began to pay the fans to attendhanding over vouchers at the turnstiles that could be exchanged in the clubs' networks of shops, schools, off licences, hospitals and other outlets.

The rise of the professional football fan as the region's main source of income was a rapid - and to economic and social experts, astonishingly widespread - development. By ' 44 - when the veteran Consul Johnson retired from public life to be replaced by his grand-daughter Livia $-88 \%$ of all employment in some areas of the city was in this new profession. The success of 5D Football after that cemented the football economy into place and underpinned the subsequent evolution of Urbanitas, with its vivid tripartite red, blue and white flag with the golden football in the centre.

The City State was now divided into the Red, Blue and White zones, each dominated by a massive football arena. These dwarfed the original arenas of the early 2000s. When the Emirates stadium was built for Arsenal football club in 2006 it was the biggest sports arena in the city; it was as if a huge alien spaceship had landed, visible from so many North London vantage points. That stadium became a holding space for people waiting for information about and access to the services that Arsenal provided. Islington Borough Council's offices down the road, that used to handle thousands of citizens' queries each day, had long been re-used to provide a free lunch canteen and social care facility for the disabled.

Governance was now firmly in the hands of the football corporations. Each of the zones had its own tribune, selected by popular acclaim at the last match of each season. Under the tribunate, there were officials responsible for functions such as waste disposal and road maintenance. Planning and development was dealt with by sub-tribunes, who presented pictures of large-scale developments on giant screens to receive acceptance by acclamation at the first match of every month. Massive lines of transportation by high speed rail and underground transit moved people from the edge of the city region to attend the matches that were the financial and cultural lifeblood of Urbanitas.

By contrast, the area south of the Thames had suffered the consequences of not having a successful Premier League club in the early 2000s. Massive population shifts across the river led to major dereliction, empty spaces and a take-over by wildlife; the north might be Red, Blue and White but the south was a mass of green, when seen from the air. And this could be readily seen, as planes came in to land at the three major airports located in south London and linked by rapid hoverfleet lines to the mega-arenas of the north. London remained a global hub, but that status rested on the interest of the world in the kick of a ball.

\section{References}

UCL. 2013 (21 January). Challenging Lock-in through Urban Energy Systems. Available from: www.ucl.ac.uk/clues. [Accessed 7 August 2013] 


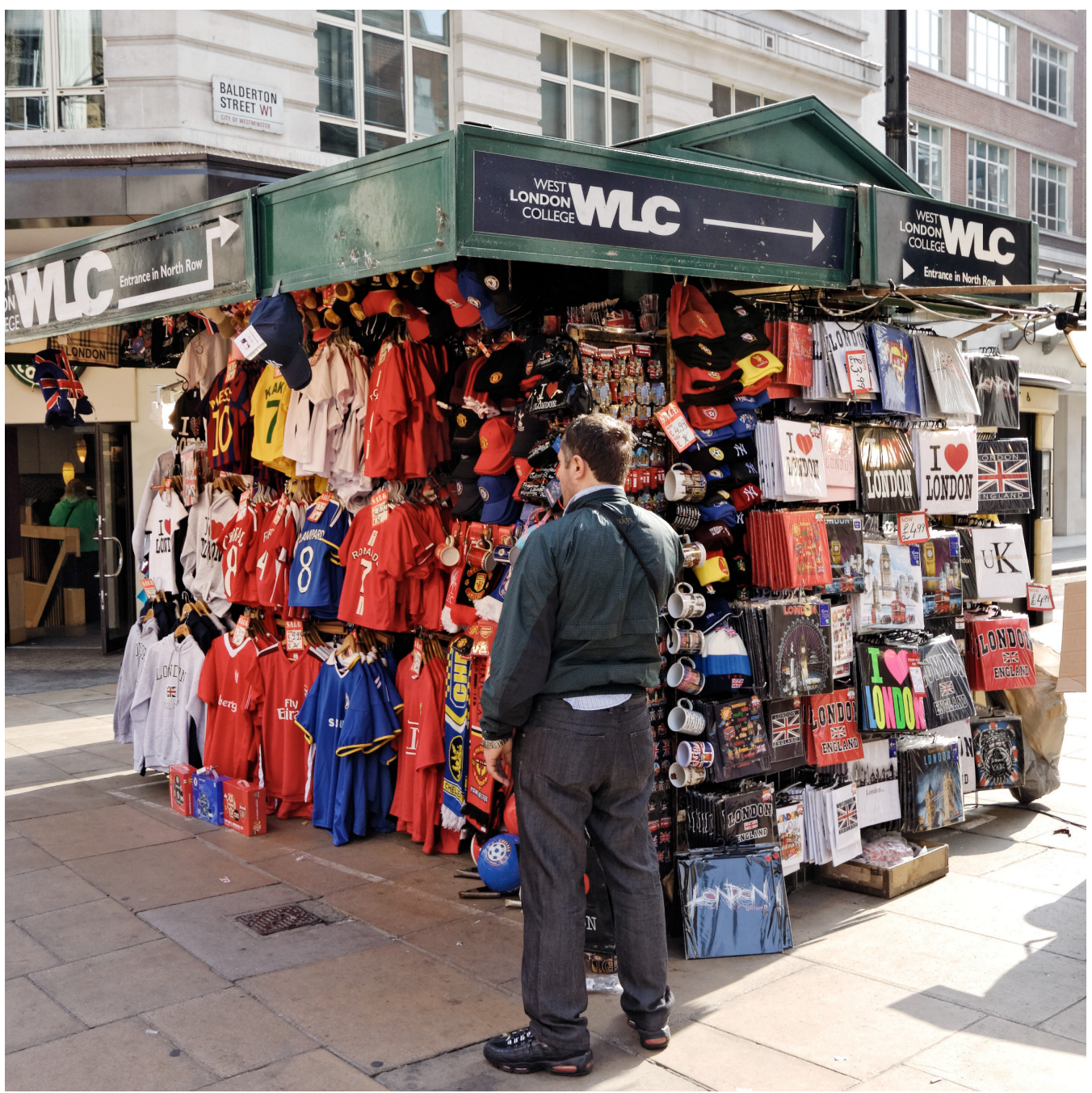

